Portland State University

PDXScholar

\title{
Bitcoins in Venezuela: Examining the Origins, Nature, and Viability of Cryptocurrencies in the Hyperinflated Country of Venezuela
}

Connor Wulf

Portland State University

Follow this and additional works at: https://pdxscholar.library.pdx.edu/honorstheses

Let us know how access to this document benefits you.

\section{Recommended Citation}

Wulf, Connor, "Bitcoins in Venezuela: Examining the Origins, Nature, and Viability of Cryptocurrencies in the Hyperinflated Country of Venezuela" (2018). University Honors Theses. Paper 518.

https://doi.org/10.15760/honors.523

This Thesis is brought to you for free and open access. It has been accepted for inclusion in University Honors Theses by an authorized administrator of PDXScholar. Please contact us if we can make this document more accessible: pdxscholar@pdx.edu. 


\title{
Bitcoins in Venezuela: \\ Examining the Origins, Nature, and Viability of Cryptocurrencies in the Hyperinflated Country of Venezuela
}

\author{
By: Connor Wulf \\ An undergraduate honors thesis submitted in partial fulfillment of the requirements for the \\ degree of Bachelor of Science in University Honors and Quantitative Economics
}

Thesis Advisor

Cesar M. Rodriguez, $\mathrm{PhD}$

Portland State University 


\begin{abstract}
The purpose of this thesis seeks to examine the origins, nature, and viability of cryptocurrencies in the hyperinflated country of Venezuela. This inquiry first considers the emergence and proliferation of cryptocurrencies as alternative currencies to the Venezuelan bolivar due to breakdown of the populist economic policies of the Chavez and Maduro regimes. The economic policies taken into consideration are the government's overreliance on oil production, a lack of private property institutions, disproportionate government spending, expansionary monetary policy, draconian price controls, and an inefficient exchange rate system which all contribute to the weakening and eventual collapse of the Venezuelan bolivar. We then shall introduce the nature and role of cryptocurrencies in Venezuela in terms of functioning as a digital, decentralized currency meeting Venezuelans' preferences and demands for goods and services in international markets in the midst of this economic crisis. This inquiry concludes by discussing the feasibility of cryptocurrencies as alternative currencies in the hyperinflated country of Venezuela. The scholarly debate of cryptocurrency viability materializes amongst economists and academics like Ehrsam, Tucker, Surda, Patterson, Dorfman, and Beliunas particularly in terms of the cryptocurrency's ability to meet the necessary characteristics and functions of money.
\end{abstract}

\title{
Acknowledgements
}

I would like to thank the Honors College, Economics Department, Mathematics Department, and my thesis advisor at Portland State University for their work in helping me become a better thinker, writer, and student over these past three years. I could not have done this without them. Thank you.

Veritas Lux Mea, the Truth is my Light 


\section{Table of Contents:}

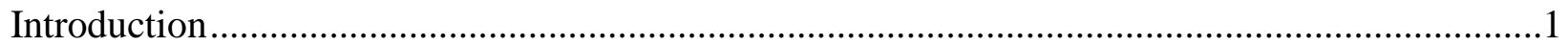

Part I: The Origins of Cryptocurrencies in Venezuela.........................................................4

Background and Economic History of Venezuela .....................................................4

Economic Policies and Effects of Chavez and Maduro ................................................

The Venezuelan Economic Crisis ...............................................................................19

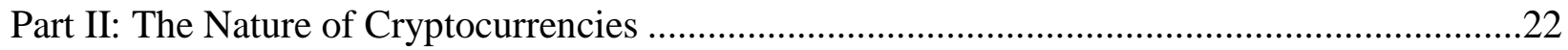

Alternative Currencies .......................................................................................22

Cryptocurrencies Background and History ..........................................................25

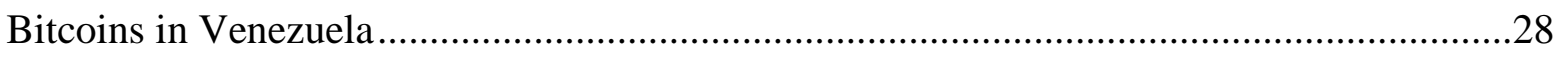

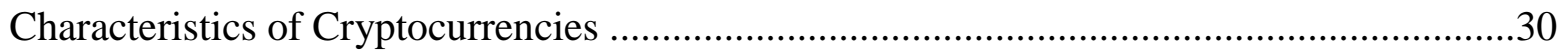

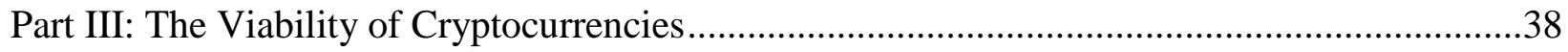

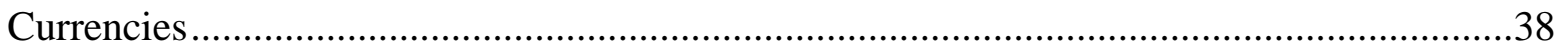

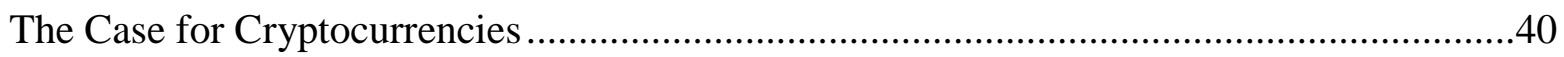

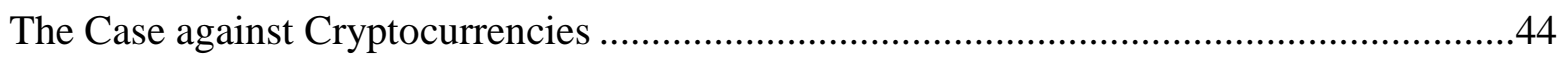

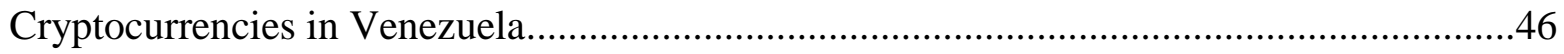

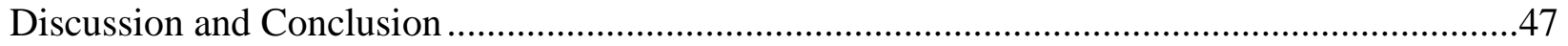

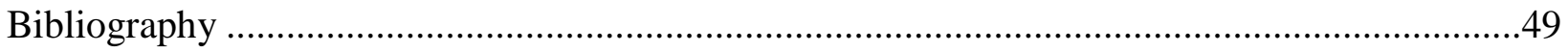




\section{Introduction}

The current economic collapse in Venezuela is widely considered to be the greatest humanitarian crisis of our time as Venezuelans protest their corrupt political regimes, struggle for basic necessities like food and medicine, and fight for survival day to day. Venezuela upholds its dominance in the news for its severe hyperinflation, high unemployment, dangerously declining GDP, constant violence, widespread starvation, and lack of any sort of available resources. According to the International Monetary Fund (IMF), the GDP per capita in Venezuela has declined by $40 \%$ over the past five years while defaulting on their foreign debt in November of 2017 (Hausmann, 2017). The International Monetary Fund (IMF) also predicts that inflation in Venezuela will hit $650 \%$ by the end of 2017 and will hit $2300 \%$ at the end of 2018 (Zuniga, 2017). This economic collapse is fracturing the Venezuelan economy as reported in terms of quantitative macroeconomic indicators but its collapse is chiefly affecting the individuals of Venezuela as identified in the qualitative microeconomic conditions of its citizens. A study by the National Survey of Living Conditions (Graham, 2017) found that the 75\% of the Venezuelan population lost an average of nineteen pounds as a result of an ongoing food shortage and lack of basic health necessities in the country. The survey also found that $82 \%$ of Venezuelans live in poverty with $34 \%$ of Venezuelans eating less than two meals a day. As 2018 commences, news agencies in and around Venezuela continue to report on the increasing riots, starvation, economic instability, and outright devastation that consumes the country (Graham, 2017).

The use of cryptocurrencies began to emerge in the late 2000s and early 2010s internationally but most profoundly in the United States and Eurozone. It's significant to note that despite concentration in western developed nations, cryptocurrencies began to remarkably propagate in Latin America particularly the country of Venezuela. Cryptocurrencies are essentially digital currencies that require technology via mobile phone or desktop computer in 
order to use the currency. Cryptocurrencies such as bitcoin, ripple, litecoin, and ethereum all have a finite supply that can exist in circulation and the currencies themselves all lack a central bank making the currency truly decentralized. These cryptocurrencies use cryptography for security which makes it difficult to counterfeit and easily accessible across borders for international trade or online exchanges. The big appeal regarding cryptocurrencies is that they are organic in nature, decentralized, not susceptible to decreasing purchasing power, and eliminate transaction fees associated with regular currencies as cryptocurrencies are not issued by a central authority and are thus immune to government manipulation or interference. As a direct result of the economic crisis, more and more Venezuelans are using cryptocurrencies as tender in order to purchase basic goods that are nonexistent in their home country. According to CNBC, there are at least a couple hundred thousand bitcoin users in Venezuela who make roughly $\$ 500$ per day (Hackett, 2017). The Venezuelan government also introduced an oilbacked cryptocurrency in late 2017 called the "Petro", which is backed by the country's oil reserves, in response to the rise of alternative cryptocurrencies, severe hyperinflation in the country, and overall economic instability particularly with regards to its foreign debt (Medium, 2018).

The purpose of this inquiry seeks to establish that the origins and development of cryptocurrencies in Venezuela relates directly to the macroeconomic and microeconomic policies implemented by the Chavez and Maduro regimes which have exacerbated the Venezuelan economy and hyperinflated the Venezuelan bolivar. These policies consisted of seizing private production of goods and services, severely controlling exports and imports, disproportionately increasing government spending, setting draconian price controls for most goods, using an inefficient exchange rate system, and enacting irresponsible expansionary monetary policy. This 
inquiry then seeks to establish that the result of these economic policies as denoted by poor economic indicators forced other means of exchange i.e. cryptocurrencies to emerge into the developing country. This inquiry then considers the costs, benefits, and functions of such cryptocurrencies to examine the nature and role of cryptocurrencies for Venezuelans. This inquiry concludes by discussing the feasibility of alternative currencies during hyperinflationary economic periods. This feasibility considers the debate between Tucker, Surda, Patterson, Durfman and Beliunas in which the cryptocurrency's ability to take on the properties, characteristics, and functions of money is discussed and examined. 


\section{Part I: The Origins of Cryptocurrencies in Venezuela}

\section{Background and Economic History of Venezuela}

Venezuela is a country sitting in the northern region of South America and is one of the most urban countries in Latin America with a population of roughly 31.5 million. Lieuwen (2017) notes that the economy of Venezuela is built up on petroleum exports and manufacturing where revenue from petroleum exports accounts for more than 50\% of the country's GDP and around $95 \%$ of total exports. Venezuela is the $57^{\text {th }}$ largest export country in the world and has a positive trade balance of $\$ 6.82$ billion where exports constitute $\$ 34.3$ billion and imports constitute \$27.5 billion (Lieuwen, 2017). According to Simoes (2018), Venezuela’s top exports consist of petroleum (refined and crude), precious metals, and other industrial related exports. Simoes (2018) also cites that Venezuela is one of the largest exporters of oil in the world and has the world's largest proven oil reserves at around 296.5 billion barrels (20\% of global oil reserves).

Venezuela has always been a giant in the petroleum and manufacturing industries. Large supplies of oil and abounding natural resources were discovered in Venezuela in 1922 and after several agreements of terms with American and international oil corporations like the Standard Oil Company and the Creole petroleum Corporation, the birth of the oil economy in Venezuela began (Lieuwen, 2017). Following years of success due to technological advances, an increase in automobile use, an increase in the demand for oil due to a world war and government legislation granting more discovery for oil production, the Venezuela economy was booming (Lieuwen, 2017). In 1950 Venezuela was ranked as the world's $4^{\text {th }}$ largest wealthiest nation per capita as the country experienced high GDP growth (roughly \$7427 compared to the U.S.' \$9573)

(Desjardins, 2017). Following this period of economic height (zenith), the Organization of 
Petroleum Exporting Countries (OPEC) was created in the early 1960s to "coordinate and unify petroleum policies among member countries in order to secure fair and stable prices for petroleum producers; an efficient, economic and regular supply of petroleum to consuming nations; and a fair return on capital to those investing in the industry" (OPEC, 2018).

Due to a steady increase in demand internationally for oil and constant high prices of oil (\$11.39 per barrel in 1976 dollars), the Venezuelan economy soared in the 1960s and 1970s (Desjardins, 2017). This economic activity led to increased government revenues which the Venezuelan government liberally spent toward public programs such as health care, transportation, education and public subsidies (Hausmann, 2014). Hausmann (2014) also notes that while the Venezuelan people and economy soared during periods of high oil prices ( $\$ 28.95$ in 1980), the economy nearly collapsed during periods of low oil prices like ( $\$ 10.85$ in 1986). Hausmann (2014) continues by stating that the Venezuelan economy thus became structured around global oil prices and so the economy contracted during shattering oil prices causing inflation to reach unforeseen levels (84.463\% in 1989) and GDP to decline rapidly (-13.9\% decline in GDP in 1989).

In 1999, Hugo Chavez came into power and initiated the "Bolivarian Revolution" as well as a multitude of populist economic policies that were designed to help the working class, reduce poverty and inequality, provide necessities for the poor, and establish social programs that are designed to greatly benefit the Venezuelan people (Hausmann, 2014). These populist policies were all possible due to booming oil prices ( $\$ 24.45$ per barrel) which thus resulted in booming government revenues for Chavez and his regime. As a result of this significant increase in revenues, Weisbrot and Sandoval (2007) note that Chavez aimed these public services to improve Venezuelan economic and social conditions by redistributing wealth, reforming land 
use, expropriating private property, restructuring the national economy, setting price controls, and controlling the distribution of private goods. Under Chavez, the Venezuelan economy became even more structured around oil production as oil production accounts for $90 \%$ of Venezuelan exports currently (Hausmann, 2014). During the Chavez years, the central government's social spending increased from 8.2 percent of GDP in 1999 to 13.6 percent in 2006 , in real inflation terms the social spending per person has increased by $170 \%$ in a duration of eight years (Weisbrot and Sandoval, 2007).

Following the death of Chavez in March of 2013, Maduro and his administration quickly took control and strictly adhered to the tenets of Chavez' Bolivarian revolution and populist economic policies (Rosati and Zarpa, 2017). Maduro was hostile to foreign businesses as government authorities seized factories and private property which forced private corporations like GM, United, and PepsiCo to leave Venezuela (Zuniga, 2016). Maduro continually increased wages for the working class and Maduro kept the overvalued exchange rate in place and resumed the government control of the economy as oil production/exportation both defined and destroyed the economy (Benzaquen, 2017). All was meagerly well up until international oil prices fell drastically in 2014 , from $\$ 110$ to $\$ 48$ per barrel, and suddenly the government was exponentially growing its deficit (Benzaquen, 2017). As a solution, Maduro decided to print more currency to cover the bill. This lead to excessively high volatility and an exponential acceleration of the inflation rate.

Venezuela's economy is currently in turmoil as inflation rates soar out of control as the International Monetary Funds (IMF) indicates that the inflation rate at the end of 2018 could rise as high as $2300 \%$, a rate so high not seen since Zimbabwe's hyperinflation crisis in the 2000 s when inflation hit an unbelievable 79,600,000,000\% (Durden, 2017). In the past four years 
Venezuela's GDP has decreased by $35 \%$ while their GDP in terms of per capita has decreased by $40 \%$ meaning that their entire economy from a macroeconomic scope has decreased by more than a third in size which is a greater contraction than the U.S. great Depression where GDP decreased by $28 \%$ (Hausmann, 2017). Not only is this affecting the macroeconomic scope of the country but it is affecting and hurting the Venezuelan people the most. Venezuela's economy also ranks among the lowest in terms of property rights and economic freedom according to Heritage (2017) as the country ranks 179 out of 180 countries, just in front of the dictatorship of North Korea. Venezuelans are unemployed, starving, rioting, and demanding economic and social justice as Venezuelans young and old struggle to survive. In a study, the National Survey of Living Conditions (2017) found that roughly 75\% of Venezuelans have lost an average of 19 pounds since the birth of the Venezuelan collapse while $34 \%$ eat less than two meals a day. This period of hyperinflation declining GDP, and outright starvation means an inability for Venezuelans to participate in the labor market and an inability use Venezuelan currency (the bolivar) to purchase goods like basic necessities that are in short supply. 


\section{Economic Policies and Effects of Chavez and Maduro}

While Venezuela's demise started back in the early $20^{\text {th }}$ century, several policies implemented by the Chavez and Maduro regimes continue to exacerbate the economy and negatively affect the Venezuelan people. It's important to note that several other factors helped contribute to the demise of Venezuela (foreign conflicts, foreign intervention, internal corruption, etc.) although the economic policies set forth by these regimes significantly affected the need for alternative currencies to arise. Macroeconomists Dornbusch (1989), Edwards (1999), Rodriguez (2018), and Hausmann (2017) all discuss the repercussions of populist economic policies particularly in terms of how they have affected countries within the Latin America continent. The first economic policy considered is the restructuring of the Venezuelan economy as the government continues to severely structure its economy and excessively control imports and exports. The second economic policy considered is the redistribution of wealth and land providing an unsatisfactory business environment for corporations as well as families. The third economic policy considered is the irresponsible government spending followed and lack of savings which failed to allow for any revenues during contractionary economic periods. The fourth economic policy considered is their unfortunate use of price controls that fail to alleviate the bill for consumers as shortages proliferate. The final economic policy considered is the unfortunate monetary policy that the Venezuelan government has undertaken which has absolutely altered the Venezuelan economy. These economic policies that have been advanced by the Chavez and Maduro regimes have plagued the Venezuelan economy and have forced cryptocurrency markets to emerge and be a viable alternative currency in an era of hyperinflation and economic instability. 
The fatal flaw of the Venezuelan economy is the over-reliance on the production of oil which is expected to be the engine of economic growth. In Chavez' 1999 constitution, Chavez heavily focused on running the state ownership of PDVSA (Petroleos of Venezuela, S.A.) like a private firm, the largest state-run oil company in Venezuela, as well as maximizing revenues (not profits) (Reuters, 2010,) .In 2006, Chavez announced a nationalization of oil production managed by foreign companies which thus resulted in an increase in of the government's shares in these projects from $40 \%$ to $60 \%$ prompting many companies like Exxon Mobil and ConocoPhillips to leave the region entirely (Reuters, 2010). At the start of Chavez' term in 1999, petroleum products as a percentage of total goods exported was roughly $68.78 \%$ but due to an increase in state intervention, this figure has increased to $96.28 \%$ (Hausmann, 2014).

Following a strike of oil workers in Venezuela in 2002, Chavez fired all oil workers (roughly 17,000) and replaced experienced, qualified oil technicians and workers with unqualified loyal followers of Chavez which signaled a significant drop in GDP from 2002 to 2003 this is referred to as Chavez' renationalization of PDVSA (Reuters, 2010). Chavez also met with the OPEC regularly and actively fought for production quotas and limiting supply in order to maintain steady international prices thus allowing for a steady Venezuelan economy (Reuters, 2010). This renationalization allowed Chavez to fully control PDVSA which focused prior on mass producing barrels of oil, regardless of any OPEC quotas but Chavez wanted to maintain a steady price of a barrel of oil from $\$ 22$ to $\$ 28$ dollars and thus renationalization allowed his policies to truly control the state production of oil (Hanson and Alvarez, 2009).

While Chavez had good intentions in terms of increasing government revenue by relying on their powerhouse of an industry, oil production, its flaw is its failure to diversify its investments, exports, and entire economy as a whole. Because oil account for $95 \%$ of 
Venezuela's export earnings and half of it budget revenue, Venezuela is unfortunately dependent upon a factor largely outside its control that is, the international price of oil. This is known as the Dutch Disease which ultimately refers to the negative consequences arising from large increases of the value of a country's currency associated heavily with focusing on a particular natural resources (C.W., 2014). The Dutch Disease causes a decrease in the price competitiveness for exports in the affected country's manufactured goods while increasing the quantity of imports resulting from an appreciated currency (Heath, 2016). This appreciated currency hurts exports of manufacturing and other industrial sectors. This sudden increase in oil production restricted Venezuela's overall ability to create, invest and maintain other industries necessary for the overall economy (Schwartz, 2016). Schwartz (2016) notes that the overreliance on oil production tends to eliminate other industries due to a lack of investment and an appreciated which accounts for goods being cheaper abroad. Venezuela used to have quite a diverse economy consisting of agriculture, industry, and horticulture but now they rely on imports for $80 \%$ of its food sources and food production accounts for as little as 4\% of GDP (Hausmann, 2014). From 1990-1999 Venezuela's industrial production declined from 50 percent to 24 percent of GDP (Hausmann, 2014). This overreliance on oil production as a result of centralized planning in one industry forces the economy as a whole to be susceptible to the boom and bust business cycle and oil prices which thus forces irregular shifts in the country's GDP as can be seen by the 7\% decrease in GDP from 2013 to 2014 (Hausmann, 2017). The government thus survives only based on the revenues from this one resource which considering the unstable and volatile international price of oil, one can expect irregular and volatile government revenues.

The implementation of redistributive land and wealth policies have also been detrimental to the Venezuelan economy and contributed to the emergence of alternative currencies. Property 
rights are essential to a flourishing economy as noted in Adam Smith's An Inquiry into the Nature and Causes of the Wealth of Nations (1776). Property rights are imperative for economic development due to their basis for economic exchange, trade, and the development of markets both markets for goods and financial markets. Property rights that are legally defined allow for individuals to commit resources to ventures and activities with full confidence allowing for investment and greater economic activity to occur without threat or fear of theft or confiscation (Alchian, 2007). Private property provides an incentive to conserve finite resources and maintain capital for future production and thus allowing individuals to exchange allowing individuals to make trades that will make both parties better off. (Alchian, 2007) Private property is essential to economic development and the regimes of Chavez and Maduro have destroyed this essential tenet for economic prosperity.

In 2001, Chavez initiated a land law that allowed the Venezuelan government to confiscate privately owned land that the government deemed as either idle, unproductive or not for appropriate use (Weisbrot and Sandoval, 2007). In 2005, Chavez took hold of hundreds of thousands of acres of land owned by private firms and individuals forcing an emergence of an uninviting and dis-incentivizing individuals to participate in the market economy (Weisbrot and Sandoval, 2007). Chavez' re-election in 2006 was based on seizing the means of production, private assets which since then have been constantly under harassment by the regime (Taub, 2017). Chavez also advocated an amended the Venezuelan constitution in 2007 to allow for public property and communal property in which he nationalized many industries and sectors of the economy (Taub, 2017). In 2015, Maduro began seizing assets, firms, and individuals who Maduro deemed weren't fully transparent with the Venezuelan government (Krauss, 2017). As a result, the government seized seventeen businesses who weren't in line with the government, 
thirty-five supermarkets, seventeen owners/shareholders who were in violation of not acting within the government's jurisdiction (Krauss, 2017). Venezuela currently ranks 127 out of 131 in terms of property rights according to the International Property Rights Index (2017).

These redistributive policies have been absolutely disastrous for business, corporations, and individuals who are employed and derive income and capital from their productive behavior with these firms. In May of 2017, General Motors shut its operations after the Venezuelan government seized its plant following Ford Motors departure in December of 2016 (Krauss, 2017). Several other companies have left the country citing economic instability and an economic environment that is bad for business, companies like Pepsi, Coca-Cola, Bridgestone, Colgate, Kimberly Clark, Mondelez, and ExxonMobil (Krauss, 2017). CNBC cites that in late 2015, Pepsi left the country of Venezuela due to sheer fear of government seizing its assets and fear of an even more unwelcoming economic future and so Pepsi left Venezuela taking on a \$1.4 billion dollar loss (Fahey and Wells, 2016). Without solidly defined property rights, the Venezuelan economy will continue to collapse and the economic incentive and price system that allows for economic growth and economic development.

Price controls are another component to the deterioration of the Venezuelan economy and the emergence of other currencies being used for medium of exchanges. Price controls are essentially government regulation establishing a maximum price to be charged for specific goods and services that is used often during war and inflation. In a free market, the market price is the price of a good or service in which the quantity supplied is equivalent to the quantity demanded. This market-clearing price is ideal as the market clears due to a lack of shortages or surpluses adhering to the law of supply and law of demand; it's an indication of the relative scarcity of a commodity and rations it to the highest demander in an economy. These market prices satisfy 
both the needs of suppliers and demanders and by engaging in a particular trade both parties are better off. These prices function as signals to both consumers and producers of how much of a product or service must be demanded or supplied respectively.

The price controls set in place by the Venezuelan government have completely disrupted the Venezuelan economy and have distorted the price system. In 2014, the Maduro Regime initiated the Fair Prices Act which banned profit margins over 30\% and tightened price ceilings on basic goods (Reuters, 2014). This Fair prices Act is Maduro's attempt to combat inflation by imprisoning those hoarding goods or "over-charging" government guidelines. The Maduro regime has also implemented a policy titled CLAPS which is a government redistributive effort to distribute food from house to house which attempts to better supply goods to those who are in desperate need (Reuters, 2014). In June of 2016, Maduro put the Defense Minister Vladimir Padrino Lopez in charge of product distribution and price controls due to mass attempts of looting in urban areas and as a result the military hoarded products, were involved in heavy corruption and significantly increased the cost of goods (Gillespie, 2017). All in all, the Venezuelan government set price controls on 400 basic foods to counter inflation and to protect the poor and set minimum production quotas for roughly the same goods which in turn led to higher inflation rates and caused more shortages which hurt those already impoverished (Gillespie, 2017).

In theory, price controls seem like a great idea as they help decrease the prices of goods (set a ceiling, suppliers can't price above) and as such more people can purchase the good or service. However, price controls are great in theory but in practice they cause more harm than they do good. In practice, the price-fixing done by the Venezuelan government has destroyed the clearing and allocating function of market prices. As a result, short-run surpluses or shortages 
become inevitable due to excess supply or excess demand as well as price increases in selected markets for similar goods, the creation of dangerous black markets for akin goods, and a continuous misallocation of scarce economic resources. Price controls have hurt the Venezuelan as can be seen by the constant shortages and long lines seen in Venezuelan supermarkets and the report from the National Survey of Living Conditions (2017) reporting a nineteen-pound decrease in weight for the average Venezuelan since the start of the Venezuelan crisis and a lack of ability to obtain three meals per day. From the implemented price control policy, the government and military benefit the most while the consumers are of the most negatively affected.

Another significant cause of the Venezuelan crisis is the reckless government spending and corresponding monetary policy that relates earlier to the overreliance on oil production. Due to Venezuela's structured economy that relies on oil production or $95 \%$ of economic output, the majority of revenues coming into the hands of Chavez and Maduro come from oil revenues (Hausmann, 2014). However, as discussed earlier, the revenues attributed to the Venezuelan are dependent upon oil prices and thus the revenues act as a function of international oil prices. Logically assuming ceteris paribus, when international oil prices are high - government revenues are high, and when international oil prices are low - government revenues are low. In the beginning of 2014 international oil prices were as high as $\$ 100$ per barrel but fast forward two years ahead and international oil prices are around $\$ 26$ per barrel - a decrease of government revenues of around $75 \%$ (Reuters, 2010).

During the oil boom, Chavez increased government spending was possible due an increase in the influx of government revenues via increased international prices of oil (Hausmann, 2014). In 2009, Chavez increased government spending to $\$ 16$ billion from $\$ 5.6$ 
billion while increasing the minimum wage by $20 \%$ and increasing taxes particularly a sales tax from 9\% to 12\% (Hausmann, 2014). At the peak of oil prices in 2008 ( $\$ 147.30$ per barrel), Chavez built a series of social programs based on the revenue earned from these high oil prices rather than keep the revenues on reserve for contractionary economic periods (i.e. the 2014 crisis) (Hausmann, 2014). While emphasizing social programs and lacking any savings for periods of economic recession, the Venezuelan economy has set itself up for disaster as seen in its current debt crisis. This drop in oil prices causes a limited access to foreign currency (the U.S. dollar), aggravates inflation, created huge shortages, limits imports, and causes the debt to increase (Hausmann, 2014).

Economist Garcia cites that the Venezuelan monetary base has increased by 1000 percent annually as a way to cover its large budget deficit that is, the amount of total money in circulation is increasing by $1000 \%$ every year (Reuters, 2017). At the end of 2016, Venezuelan President Nicolas Maduro also unveiled new Bolivar w/ denominations of 100,000, 20,000, $10,000,5,000,2,000,1,000$, and 500 eliminating the use of small denominated bills (Reuters, 2017). This mass production of currency is the Maduro regime's attempt to cover its deficits but has only increased hyperinflation to a projected high of $2300 \%$ in 2018, an inflation unforeseen in modern Latin American history (Hausmann, 2014).

The final component to the collapse of the Venezuelan economy is their currency controls and their exchange rate fixing. In January 2003, the Chavez regime implemented strict currency controls which made it more difficult for investors to exchange bolivars for dollars (Bajpai, 2015). The government created CADIVI which is a currency control board charged with handling foreign exchange procedures. At the same time, the Venezuelan government suspended trading of the bolivar as it continuously plummeted in value (Disilvestro and Howden, 2016). 
This was an attempt by the Chavez regime to protect Venezuela's foreign reserves by setting a fixed rate for the dollar, to prevent capital flight, and maintain the stability of the bolivar after several oil strikes and as a result, there were a series of devaluations disrupting the macroeconomic stability of the country (Disilvestro and Howden, 2016). Disilvestro and Howden (2016) note that the Chavez regime also introduced several exchange rates: CENCOEX for the importation of food and shortages (6.30 bolivars to the dollar), SICAD I (12 bolivars per dollar), SICAD II (50 bolivars per dollar) which like SICARD I assigns dollars to enterprises that import all other types of goods, SIMDAI is the last exchange rate and this rate is reserved for the purchase and sale of foreign currency to individuals and businesses (200 bolivars per dollar).

A direct result of this economic policy is that the Venezuelan government will have direct say over who gets U.S. dollars and who doesn't. At the time of the implementation of the policy, the exchange rate between the U.S. dollar and Venezuelan Bolivar was 1.6 but ten years with constant government intervention and currency controlling policies, the exchange rate is roughly 172 bolivars for every U.S. dollar which is a devaluation of about 99\% (Disilvestro and Howden, 2016). When looking at the black market, the exchange rate is nearly 900 bolivars to the U.S. dollar (Disilvestro and Howden, 2016). This massive devaluation is detrimental for consumers who must deal with high degrees of price inflation and for businesses that must undergo longterm capital planning decisions with a constantly changing monetary unit (Disilvestro and Howden, 2016). This massive volatility of the exchange rate caused by the government's currency restrictions and exchange rates will deter any sort of participation by consumers, investment by businesses, and trade amongst parties, and will further lead to economic instability (Disilvestro and Howden, 2016). 
The complex exchange rate system allows for limited exchanges to occur due to the difficulty to actually get assigned these rates by the bureaucracy and thus Venezuelans must rely on the black market to meet their demands for foreign currency which is obviously much less advantageous at 900 bolivars versus 6.3-200 on the government regulated market but more reliable to meet their demands for foreign currency exchange (Disilvestro and Howden, 2016). The corruption involved also plays a huge role as officials within the government benefit the most from this mismanagement of money as they can obtain U.S. dollars through legal channels (low prices) but then sell them on the black market for a higher price, the definition of arbitrage (Disilvestro and Howden, 2016). Due to the stability, strength, and relativity high value of the U.S. dollar, embezzling also occurring which is preventing any sort of importation of basic goods which leads to unpaid imports, business owners with no options to import goods, foreign exchange shortages, and shortages of goods hurting consumers in Venezuela (Disilvestro and Howden, 2016). This complex and inappropriate exchange rate system allowed for the blackmarket rate to proliferate since Venezuelan business owners rely on foreign goods that require payments with reliable foreign currencies (Disilvestro and Howden, 2016). Due to the government's holding of reliable currencies, Venezuelans must resort to the black market and as such raise the merchant's price on consumers (Disilvestro and Howden, 2016). Due to the price controls already in place as discussed earlier, businesses make little profit due to this and as such, shortages proliferate due to the inability to import the goods that Venezuela is so heavily reliant on. By using the black market rate, businesses in the Venezuela economy will have no way to maintain stable prices for the products the import which represents a huge disruption of the market (Sanchez and Goodman, 2014). A great example of this is Venezuela's largest food supplier, Empresas Polar, which owes 463 million U.S. dollars to foreign suppliers (Sanchez and 
Goodman, 2014). The most recent study back in 2014 focused on the significance of shortages in the country of Venezuela and the study revealed that $22.4 \%$ of necessary goods are not in stock (Sanchez and Goodman, 2014). In summary, shortages, high inflation, and further devaluation of the bolivar are the direct result of these exchange rate policies (Sanchez and Goodman, 2014). 


\section{The Venezuelan Economic Crisis}

It is clear: the Venezuelan economy is crashing and the macroeconomic and microeconomic policies implemented by Chavez and Maduro have played a huge role in its exacerbation as well as the emergence of cryptocurrencies in Venezuela. The government has restructured its economy to focus solely on oil revenue and due to the nationalization of oil corporations and production, the economy has just become inefficient and unfortunately has become over-reliant and susceptible to the international price of oil. The redistributive land and wealth pieces of legislature have destroyed the incentive system and one of the essential institutions for the propensity for economic growth. The price control populist policies have distorted the price system and have furthered hyperinflation and led to widespread shortages. The government spending and in turn, monetary policy to cover the deficits, implemented by the Chavez and Maduro regimes have severely increased the inflation rate and distorted the imports entering the country and in turn have caused shortages. The final component is the currency controls and fixed exchange rates which have turned to more government corruption, inefficiency, increased inflation, and shortages.

These populist policies of import and export construction, redistribution of wealth, massive government spending, monetary policy, price controlling, currency controlling, and exchange rate controlling have all poor economic effects and the economic indicators in Venezuela all tell the same story of high inflation, massive shortages, starvation, political turmoil, a devalued currency, economic inefficiency, and overall economic instability. The story is that Venezuela is experiencing inflation as high as $2300 \%$, GDP has decreased by almost $1 / 2$ over the past five years, and the government has enacted and continues to ratify unfavorable 
economic policies that hurt consumers, business owners, and domestic companies, as well as foreign entities.

Due to the economic instability, there are a few options or paths to try and resolve this economic crisis but the "correct" solution is quite up to debate. One of economist Francisco R. Rodriguez argues that the simple step would be to eliminate Venezuela's huge budget deficit as the government would get more local currency for every barrel of oil sold (Rodriguez, 2016). Rodriguez (2016) argues that this attempt would help lower inflation because there would be no need to print excess bolivars in order to operate as a state and importers would no longer feel the urge to attain cheap dollars and instead would buy imported goods which would assist the economy tremendously. Another economist, Ricardo Hausmann (2017), who often disagrees with economist Rodriguez, agrees with Rodriguez that the unification of exchange rates would be an important step in economic reform for Venezuela and due to the extreme exchange rate differential, that currently exists.

The answer to the Venezuelan crisis is not simple but there are several ways governments or independent central banks (not present in the case of Venezuela) can help deter hyperinflation whether it be through contractionary monetary policy by reducing the monetary supply by reducing bond prices and increasing interest rates, increasing reserve requirements on the amount of money banks are legally required to hold on hand for withdrawals, or by directly/indirectly reducing the money supply by engaging in policies to reduce the money supply (exchange rate stabilization or monetary stabilization). Periods of hyperinflations have existed in the past century with examples including Germany in the early 1920s, Hungary after world war two in the 1940s, Chile in the 1980s, Argentina in the 1980s, Ecuador in the 2000s, and Zimbabwe in the late 2000s. For the majority of these countries in severe economic turmoil akin to Venezuela 
(Germany, Ecuador, Argentina, and Zimbabwe), currency substitution or pegging a currency on the gold standard or dollarization has been perhaps the most credible solution. Currency substitutions are essentially the use of a foreign currency either with or instead of a domestic currency and have historically been used in attempts to resolve cases of hyperinflations (Amadeo, 2018). 


\section{Part II: The Nature of Bitcoins in Venezuela}

\section{Alternative Currencies}

While the Venezuelan government continues to struggle on resolving its debt crisis, economic inefficiencies, and outright economic turmoil, more and more Venezuelans are turning to alternative currencies in the short run instead of its national currency (Chun, 2017). The bolivar, the currency of Venezuela, is extremely hyperinflated and lacks any sort of functionality as either a medium of exchange, unit of account, or store of value in this economy. The bolivar, as a result of the macroeconomic and microeconomic policies stated above, has become useless as a currency. A great example of the massive devaluation can be seen in the following example. At the start of 2017, 3,100 bolivars were needed to buy 1 U.S. Dollar (Gillsepie, 2017). On November 1 2017, 41,000 bolivars were needed to buy 1 U.S. dollar and on November 21, 2017 84,000 bolivars were needed to buy 1 U.S. Dollar (Gillespie, 2017). The IMF in turn suggests that in 2018, the inflation rate in Venezuela will hit roughly $2300 \%$ while many Venezuelans struggle to make ends meet and buy basic goods (Gillespie, 2017). Many international news agencies in and around Venezuela are reporting that many shopkeepers have been forced to weigh wads of cash instead of counting the individual bills due to the multitude of dollars needed to buy basic goods (England, 2017). The Independent (2017) reports that Venezuelans have been stuffing huge volumes of cash in handbags, money belts, and backpacks as way to buy goods in the market. This hyperinflation that Venezuela is experiencing has completely destroyed the purchasing power of the bolivar (PPM), making the purchasing power of an individual using the national currency almost worthless.

While the Venezuelan government continues to preserve and implement populist policies that have been seen to hurt the economy and individuals within the economy, Venezuelans need 
access to goods, necessities, and services to properly live their lives and survive. It's clear that the Bolivar cannot access as a medium of exchange, a store of value, and a unit of account - the necessary properties of money. Money is necessary as it used to intermediate the exchange of goods and services as it is more efficient than a barter system which suffers for the indivisibility problem, double coincidence of wants problem, and inadequately fails to maximize welfare derived from trading and exchanging goods.

In his famous piece, An Inquiry into the Nature and Causes of The Wealth of Nations (1776), Adam Smith writes on the importance of money in that "No society can surely be flourishing and happy, of which the greater part of the members are poor and miserable. It is but equity, besides, that who they feed, clothe, and lodge the whole body of the people, should have such a share of the produce of their own labour as to be themselves tolerably well fed, clothed, and lodged." Adam Smith argues here that when too many people don't have functioning money or lack thereof, that there cannot be a flourishing society. This is the epitome of what is occurring in Venezuela as Venezuelans struggle and suffer from a lack of a stable and sound monetary system and economy for that matter. In an economy, with an impaired monetary system and an economy that fails to have a functioning currency, employ labor capital, provide incomes to citizens, and supply goods at the market for proper exchange, ulterior methods must be employed. This is the case for an alternative currencies.

As a result of this economic turmoil, more and more Venezuelans are turning toward alternative, decentralized currencies that aren't regulated by the state (Chun, 2017). By definition, alternative currencies are "currencies that are used in conjunction with national currencies but are typically not legal tender and not printed or regulated by the government entity in which the currency is used" (Schwartz, 2008). Alternative currencies typically exist outside 
the realm of monetary policy and tend to be decentralized. In Venezuela, the use of alternative currencies has skyrocketed simply due to the failure of the national currency and the need for a proper currency to act as a medium of exchange, a store of value, and a unit of account. Peter North (2008) at the University of Liverpool notes that "when money gets dried up and there are still needs to be met in society, people come up with creative ways to meet those needs." One of the biggest alternative cryptocurrencies both in Venezuela and globally, is the cryptocurrency Bitcoin. 


\section{Cryptocurrencies Background and History}

Cryptocurrencies are digital assets that are designed to work as a medium of exchange which uses cryptography to secure its transactions, to control the creation of additional units, and to verify the transfer of such digital assets (Martucci, 2017). Modern examples of cryptocurrencies that are currently in existence are Bitcoin, Ethereum, Litecoin, Ripple, Coinye, and many others. The cryptocurrency's block chain is the master ledger which stores and records all prior transactions and activity, validating ownership of all the units of currency at any given time (Martucci, 2017). It's important to note that cryptocurrencies are not regulated by a national government or entity as the control is decentralized due to supply and value for the assets being derived from the activity of the users and the very complex protocols involved with the governing coding. The supply of bitcoin units is decentralized and is derived from a finite supply which the source codes outline the precise number of units that can be mined and that can exist in circulation and as it reaches the finite supply, new units of currency units cannot be minted (Martucci, 2017).

The supply of cryptocurrencies relates to the work of what is called cryptocurrency miners. Cryptocurrency miners serve as record keepers for cryptocurrency transactions and are indirect arbiters of the value of cryptocurrencies (Martucci, 2017). Miners use very large amounts of computing power (electrical energy) to verify the completeness, accuracy, precision, and security of cryptocurrencies' block chain (Martucci, 2017). The large amounts of energy are required in order to solve complex mathematical puzzles/problems which is performed by high powered computers thus the high energy is required for its self-sustaining character. The term miner refers to the fact that miners work to literally create wealth in the form of brand new cryptocurrency units. Every newly created block chain copy comes with a two-part monetary 
reward that is, a fixed number of newly minted cryptocurrency units and a variable number of existing units collected from optional transaction fees paid by buyers (Martucci, 2017).

Cryptocurrency mining is a potentially lucrative side business for those with the resources to invest in power and hardware intensive mining operations. Mining, which is not a difficult process to undertake technologically in terms of costs or technical knowledge, periodically produces new cryptocurrency units and most cryptocurrencies are designed to have a finite supply and thus as time progresses miners will mine fewer new units per new block chain (Martucci, 2017).

Cryptocurrencies aren’t just a twenty-first century phenomenon. Brian Martucci (2017) cites that cryptocurrencies have existed as theoretical constructs long before the first digital alternative currencies debuted in the late 2000s and early 2010s. Martucci (2017) notes that the intention of cryptocurrency proponents was to share the goal of applying advanced mathematical and computer science principles to "solve" practical and political shortcomings of fiat currencies. Cryptocurrency's technical foundations date back to the early 1980s when an American cryptographer, David Chaum, constructed a "blinding" algorithm that remains central to modern wed-based encryption. This "blinded money" algorithm allowed for secure, unalterable information exchanges between parties, laying the foundation for future electronic currency transfers (Martucci, 2017). After commercialization of the blinded money concept, several cryptocurrency-lite currencies emerged like DigiCash in the 1980s, b-money and Bit Gold in the 1990s, and e-gold in the 1990s (Martucci, 2017). These cryptocurrencies all started with very promising potential however for a variety of reasons (lack of investment, lack of security, and limited trading deals), these cryptocurrencies all faded out and never gained traction in the market economy. 
Bitcoin is arguably the first modern cryptocurrency to be used publicly as a medium of exchange including decentralized control, user anonymity, record-keeping via the block chain, and built in scarcity. Following the global economic recession in 2007 and 2008, a Satoshi Nakamoto, a pseudonym, released Bitcoin to the public and in 2010 the cryptocurrency was values for the first time as the first transaction of two pizzas for 10,000 bitcoins took place (Cove, 2017). Bitcoin is simply a cryptocurrency that can be used as a medium of exchange for other currencies, products, and services. Every cryptocurrency holder has a private key that authenticates their identity and allows them to exchange units. These cryptocurrency users also have "wallets" stored in the cloud with unique information that confirms them as the temporary owners of their bitcoin units (Cove, 2017). According to Metcalfe's Law, the inherent value of the Bitcoin network grows exponentially as more users participate in it (Durden, 2017). For example, in March of 2010, 1 bitcoin could buy you .003 of a U.S. dollar but in December of 2017, 1 bitcoin could buy you 17,900 U.S. dollars (Durden, 2017). While the value of Bitcoin continues to generally increase, its prices are unstable and dangerously volatile. Bitcoin has a tendency to go through various appreciation and depreciation cycles that seem related to bubbles and busts of the business cycle as can be seen on December 22, 2017 Bitcoin lost a third of its value in 24 hours as its price fell below $\$ 14,000$ (Durden, 2017). Bitcoin currently has a price of around \$11564.38 (Durden, 2017). 


\section{Bitcoins in Venezuela}

While Bitcoin, and most other cryptocurrencies for that matter, originated and have been used mostly in the United States of America and Eurozone, Bitcoins have been exploding recently in other markets but none more so than Venezuela (Chun, 2017). The use of cryptocurrencies in Venezuela have skyrocketed in recent years. Joseph Young (2017) found that in a three-month period (June 2017 to September 2017) that the trading volume of LocalBitcoins, an exchange system for bitcoins, had quadrupled from 9 billion bolivars to 40 billion bolivars. The number of Venezuelans using cryptocurrencies is unknown from government economic data due to the government ultimately ruling that the use and mining of operations of bitcoin are outright illegal. However, according to Bitcoin, Bitcoin trading numbers in Venezuela have soared from $\$ 225,000$ at the beginning of 2017 to approximately $\$ 2.1$ million (Armario and Sanchez, 2017). Joshua Althauser (2017) notes that Bitcoin is becoming a constant part of many Venezuelans' everyday life and cites that Bitcoin is now a common mode of payment for many Venezuelans whether they are buying food, plane tickets, or even paying employees.

Cryptocurrencies can be seen in the developed world as a means for investment and not so much as a means of exchange but Althauser argues that for Venezuelan, these cryptocurrencies allow for access to goods and services in new markets which thus means survival

One Venezuelan, John Villar, cites that the national currency has become worthless and thus sticks with bitcoin for all of his transactions (Armario and Sanchez, 2017). John Villar states that thousands of ordinary Venezuelans are turning to the world of cryptocurrency to salvage what's left in their savings and that it's a matter of survival, not politics (Armario and Sanchez, 2017). He also notes how easy it is as anyone with a smartphone can access websites like LocalBitcoin or Colibit which act as exchanges to buy and sell bitcoins using a local bank 
account (Armario and Sanchez, 2017). Rafael, a Venezuelan, uses bitcoin to import goods that are no longer available in Venezuela and resupply his store's shelves (Althauser, 2017). Fernando, another Venezuelan, is a bitcoin miner who uses the monthly revenue to buy insulin and other medical supplies from overseas (Armario and Sanchez, 2017). David, another Venezuelan, imports basic staples from a Miami based courier service and uses amazon gift cards as a means of exchange which he buys with bitcoins (Althauser, 2017).

This kind of financial activity and exchange with bitcoins in Venezuela is a common occurrence. Colibit founder Rafael Useche cites that Venezuelans are taking refuge in digital currencies (Armario and Sanchez, 2017). One of the significant components that makes mining bitcoin so easily accessible is that the Maduro regime heavily subsidizes electricity and thus this virtually free resource can be used by individuals in Venezuela to mine bitcoin with very little transaction cost. Althauser (2017) notes that basic mining in Venezuela for struggling citizens can earn roughly $\$ 500$ a month which is enough to feed a family and provide basic needs like household goods, food, and medications. Bitcoin ultimately allows users in Venezuela to import food, medicine, and other goods through e-commerce sites like Amazon, Walmart, and many others thus circumventing the capital controls and policies that made it impossible for Venezuelans to purchase foreign goods with the Venezuelan bolivar. The Venezuelan government has already set up policies and actions to deter this cryptocurrency emergence by having police arrest any bitcoin or other cryptocurrency miners (Young, 2017). 


\section{Characteristics of Cryptocurrencies}

Unofficial reports project that roughly a couple hundred thousand Venezuelans are actively using Bitcoins as a medium of exchange (Aru, 2017). In the America Quarterly Report, Ehrsam (2015) notes that the early impact of Bitcoin will be greatest in markets where it "enables opportunities not possible within the framework of existing alternatives." Ehrsam (2015) also argues that in developing countries, "Bitcoin provides the necessary infrastructure to enable more efficient remittances, a hedge against inflationary economies and a low-cost way to boost financial inclusion”.

In terms of monetary theory, cryptocurrencies are ultimately hardwired for scarcity meaning that there is a finite supply of currency for the population to use (Acheson, 2018). Bitcoin is not regulated by a central bank like the central bank in Venezuela or the Federal Reserve in the United States and thus is a total decentralized currency. This kind of currency has absolutely zero risk of policy-induced hyperinflation as seen earlier with the Chavez and Maduro regimes' macroeconomic and microeconomic policies all affecting the purchasing power of the bolivar and leading to the hyperinflation crisis today. Cryptocurrencies, Bitcoin for example, are different. Bitcoins aren't regulated by a central authority and thus aren't functions of monetary policy and aren't related to the individual health of an economy. Bitcoins have a maximum supply of 21 million bitcoin units where 14 million units are currently in supply (Acheson, 2018). In cryptocurrency theory, the number of bitcoins generated per block decreases by half or roughly decreases every four years (Acheson, 2017). The present value of bitcoins or cryptocurrencies for that matter is derived by individuals buying and selling in a global, open marketplace. Cryptocurrencies are also digital assets and so can be divisible into much smaller units than any other fiat currency thus enabling new types of commerce such as real time pricing 
of low cost utilities (Acheson, 2018). It's important to note that cryptocurrencies offer a reliable means of exchange outside the direct control of national banks as central banks participating in quantitative easing (central banks printing money by purchasing government bonds) or near zero interbank lending rates (Acheson, 2018). In the long run, many economists, political scientists and even the International Monetary Fund (IMF) plans on incorporating some aspects of cryptocurrencies to fiat currencies (Hackett, 2017).

While a decentralized international currency that is not regulated can be seen as unsecure, dangerous, or manipulative, the mining process acts as a way to incentivize quality control, security, and privacy of its transactions on its blockchains and of its participating individuals (Golman, 2018). Mining is a built-in quality control and policing mechanism for cryptocurrencies as miners are incentivized and paid for their efforts (Golman, 2018). These miners have a financial stake in keeping accurate, up-to-date transaction records thus keeping the integrity and the value of the currency (Golman, 2018). The up to date transactions al occur on the blockchain which acts as a digitized, decentralized, public ledger of all cryptocurrency transactions. This blockchain allows market participants to keep track of digital currency transactions without central recordkeeping (Bauerle, 2017). The Blockchain also allows for transactions to be non-duplicable and non-immutable meaning that accuracy and precision are of chief concern (Bauerle, 2017). With a currency that lacks the security infrastructure akin to a bank which has private account numbers, solid security infrastructure, and holds physical reserves in the event you wanted to withdraw from your bank account, the nature of cryptocurrencies can be scary for individuals who would prefer security knowing their funds (cryptocurrencies) are secured (Golman, 2018). Privacy and anonymity are chief concerns of 
cryptocurrency users and thus, cryptocurrencies have a blockchain network and a strong mining process to self-sustain and protect its infrastructure and currency network.

Cryptocurrencies are perhaps most sought after most due to the overall inability for foreign entities to trace funds and the low cost, efficient transactions that occur as a result. Transactions that use cryptocurrencies as currency are almost done simultaneously as you don't need any credit/debit card information and just need your cryptocurrency wallet available which has no cost associated with it. The amount will credit to the recipient within a few seconds making the ease of transfers quick and desirable unlike today's banking world where charges remain pending and can take several business days to post (Martucci, 2017). There really are no third parties and low transaction costs, thus maximizing the efficiency of a transaction for both the consumer and seller. When looking at repressive countries, if citizens run afoul of their governments, these governments can freeze or seize their assets, domestic bank accounts, or reverse transactions made in local currency (Martucci, 2017). With the use of cryptocurrencies, state seizures are theoretically impossible due to cryptocurrencies enhanced security features and cryptocurrencies being stored in the cloud, not being physical assets. This ultimately benefits consumers in countries ruled by repressive regimes like Venezuela in which their financial property and assets are susceptible to government confiscation or seizure (Graham, 2017).

Cryptocurrencies also are generally cheaper than traditional electronic transactions (Martucci, 2017). Cryptocurrencies security features like block chains, private keys, and wallets, as discussed earlier, solve problems like double spending, fraud and overall transparency. These features allow for cryptocurrencies to be more cost-efficient for consumers as they allow for cheaper transaction costs, minimize the use of third parties (like Visa or PayPal which charge 1$3 \%$ transaction fees) for payment authentication, verification, and processing. The use of 
cryptocurrencies eliminates these transaction fees as cryptocurrency miners bear the burden of the fee and are rewarded by potential new cryptocurrency units (Martucci, 2017). International transactions have also been significantly cost effective due to the low barriers and low costs of international transactions as theoretically there is no difference between parties domestically and internationally (Martucci, 2017). With international transactions involving fiat currency like the Venezuelan Bolivar, there exists special transaction fees including direct international money transfers, international credit cards, ATM fees, custom fees, and exchange rates that negatively affect your Purchasing power of money (Martucci, 2017). Cryptocurrencies are useful in this way as they minimize the burden for consumers particularly Venezuelans who rely heavily on imports and are thus discouraged from participating in the global economy due to exaggerated exchange rates, currency controls, and price controls.

Cryptocurrencies clearly have multiple benefits that can aid individuals but there are great consequences associated with them that certainly can deter or vex consumers. Cryptocurrencies have a tendency to facilitate black market activity such as money laundering, illegal drug purchases, human trafficking and other illicit activity (Martucci, 2017). While cryptocurrencies are for the most part heavily unregulated, decentralized, and untracked as this is perhaps the biggest appeal, the currency itself does participate as a means of exchange for activity that is illicit, dangerous, and unethical which can bear a heavy burden on users using the currency (Martucci, 2017). While this is a great moral and unethical issue, it should be noted that other currencies such as the U.S. dollar, Venezuelan Bolivar, Japanese Yen, etc. are used for, in some ways at least, fraudulent or illicit behavior.

Cryptocurrencies are also heavily used in cases of tax evasion because they aren't regulated by a governmental entity and aren't functions of normal monetary theory from central 
authorities, as the stock and flow of currencies cannot be tracked (Martucci, 2017). Online sellers, employers, and individuals all participate in cryptocurrency transactions to avoid sales taxes, payroll taxes, income tax liabilities, and while the IRS applies the same taxation policies to cryptocurrencies in the U.S., several other governments haven't adapted to this level of intricacy of tracking cryptocurrencies especially with pseudonyms and anonymity being used so heavily (Martucci, 2017). In general application, it proves problematic particularly when diving into deeper macroeconomic topics of taxation and fiscal policy that these cryptocurrencies can be problematic. Further social contracts, infrastructure, and policy is needed to deter this issue. Perhaps the greatest consequence of using cryptocurrencies is the possibility of the loss of financial capital whether it be via hacking, theft, unreliable storage devices, or technical glitches (Martucci, 2017). Because cryptocurrencies are stored in the cloud and on storage devices like a flash drive or cell phone, there exists a risk of theft and hacking that is not seen with common fiat currencies. On December 7, 2017, roughly \$64 million worth of bitcoins was hacked on CoinHash, one of the cryptocurrency exchanges (Iyenger, 2017). On January 28, 2018, a whopping \$534 million worth of bitcoins was stolen again via one of the security exchanges (Shepherd, 2018). With these tremendous losses, Bitcoin users whom lost their cryptocurrencies are unable to retrieve their financial capital as can be done with large banks with regular fiat currency.

Cryptocurrencies also lack the financial, technical, and capital infrastructure needed to be used as a proper medium of exchange (Martucci, 2017). Very few websites and companies accept cryptocurrencies as a medium exchange. A currency is only as useful as those willing to accept and in return use it again as means of exchange. In the United States, the United States Dollar is a successful currency partially due to the infrastructure established to accommodate 
such currency, a high frequency of usage, and a widespread acceptance of the individuals agreeing via a social contract that this currency is a valuable medium of exchange worthy of use. Cryptocurrencies lack both of these as the average store does not have the technological infrastructure to accept bitcoin due to relative high fixed costs to adapt to such technology (Martucci, 2017). Cryptocurrencies also lack widespread usage as they are facilitating greater influxes of users but questions of cost efficiency remain. Currently only scattered large retailers, various online platforms, and a few stores accepting cryptocurrencies as a medium of exchange. Given this limiting factor, this thus inhibits the functionality of cryptocurrencies and in certain circumstances make the currency impractical and inaccessible (Martucci, 2017). This could propose a problem to Venezuelans who desperately need access to large, open markets at the lowest cost possible.

The most discussed and widely known consequence of cryptocurrencies is the volatility of cryptocurrencies. Volatility simply refers to the pricing behavior of securities and the fluctuations that happen in the short run. Bitcoin, for example, is incredibly volatile as its price per coin started at $\$ 1,000$ in the beginning of 2017 and ended 2017 at an all-time high of $\$ 19,843$, an increase in value of more than $1300 \%$ (Kleinman, 2018). Despite this value accumulation, Bitcoin continues to be susceptible to massive, almost dangerous, volatility. On December 22, 2017, Bitcoin's value fell sharply by $21 \%$ in a period of less than 24 hours, falling from $\$ 15,561$ to a low of $\$ 12,504$ (Kleinman, 2018). On January 16, 2018, Bitcoin's value plunged by another $25 \%$ to $\$ 10,300$ which is down $47 \%$ from December's all-time high (Kleinman, 2018). During 2013, its volatility was 3-4 time higher than that of a typical stock, and its exchange rate with the U.S. dollar was about ten times more volatile than other currencies like the euro or yen (Kleinman, 2018). This volatility isn't just associated with Bitcoin as other 
crypto-assets like Ethereum, Litecoin, and Ripple all report similar fluctuations in asset value. This type of volatility (both rapid increases and decreases) is due to news regarding security breaches that worry investors, bad press affecting rate of adoption, a fluctuation in perceived value, great uncertainty in the risk involved, significant variance in the perception of the method of valuation, a variance in liquidity methods, and uncertain global growth (Martucci, 2017). There exist arguments that translate this volatility toward that of a market bubble similar to the "dot com" bubble of the late 1990s and early 2000s. Many argue that bitcoin is a bubble and that it's simply an overhyped phenomenon that is akin to a modern penny stock and one day it's going to burst just like the dot com bubble and so many bubbles before (Martucci, 2017).

The nature and characteristics of cryptocurrencies as a whole is in complete contrast with the fiat currency system, which is a currency that a government in a particular country declares as legal tender like the bolivar in Venezuela or the U.S. dollar in the United States. Most organized and developed countries in the modern world have implemented and retain a fiat currency system (Hall, 2015). Fiat money is based on the faith and credit of the economy and its value is derived from the relationship between the monetary supply (typically under the control of the central bank) and the demand for money. The most important component of the fiat monetary system is that it gives central banks the ability to print or hold money thus affecting monetary supply, interest rates, and general liquidity of assets thus giving central banks, like the Federal Reserve, greater cushioning power to act in times of recession (Hall, 2015). The main concern here is that this gives central banks perhaps too much power to affect inflation, purchasing power of money, and the ability to completely obliterate the store of value feature of fiat money despite the ability to enact expansionary monetary policy (either increasing the monetary supply, lowering interest rates, or increasing aggregate demand) (Hall, 2015). The 
nature of cryptocurrencies particularly in Venezuela arises due to a severe fault in the fiat currency, the Venezuelan bolivar. The severe fault being that the fiat currency was susceptible to the populist economic policies implemented by the regimes of Chavez and Maduro resulting in a shortage of resources, economic instability, a sharp 35\% reduction in GDP over the past 5 years, hyperinflation projected of around $2300 \%$, and a purchasing power of money around zero. Thus, leading to the emergence and proliferation of alternative currencies like cryptocurrencies in Venezuela which were demanded by suffering individuals within the country who needed access to larger, open markets as the current local markets failed to provide for their demands and basic needs. 


\section{Part III: The Viability of Cryptocurrencies}

\section{Currencies}

Given the hyperinflationary crisis in Venezuela, the nature of cryptocurrencies themselves, and rapid technological change within Venezuela, the question remains: are cryptocurrencies viable alternative currencies during hyperinflationary periods (given that the fiat currency, the Venezuelan bolivar, has clearly failed)? In order to facilitate this discussion, one must look at the modern day definition of alternative currencies and money. Alternative currencies are currencies which are not the national currency of a particular currency and thus are not denoted as legal tender (Gross, 2014). The use of alternative currencies is based on a social agreement between the buyer and the seller exchanging the currency. While most alternative currencies consist of local currencies or various non-nationalized currencies, cryptocurrencies fit this definition but due to their recent implementation, are these cryptocurrencies viable alternative currencies in the sense that they meet the economic conditions and definition of money that is typical current fiat money meet.

In terms of money, a currency needs to satisfy three key functions to properly fit the economic definition. It first needs to act as a proper medium of exchange eliminating key issues of a lack of double coincidence of wants and the divisibility problem. A good currency must be demanded by the seller of a particular good while being socially agreed upon by the parties participating in the exchange. The second function of money is that it needs to act as a store of value meaning that a particular or asset will maintain its value over time especially during inflationary (hyperinflationary) periods. This is arguably one of the more important aspects when it comes to looking at cryptocurrencies in Venezuela particular due to the lack of the store of value feature with the bolivar. The final function is that money needs to be act as a unit of 
account in the sense that it must be consistent in order to represent the real value of any economic concept that can be quantifiable in terms of monetary value. This allows for proper financial accounting and economic analysis which allows for meaning interpretation of prices, costs, and profits.

William Jevons prompts the discussion on money and currency with his treatise on Money and the Mechanism of Exchange (1875) defining functions of money and the properties of money that best facilitate their functions. In Chapter V of his treatise, Jevons (1875) notes the importance of the properties of money in furthering the functions of money with the key properties being utility and value, portability, indestructibility, homogeneity, divisibility, stability of value, and cognizability. Jevons (1875) notes that money takes on various functions amongst various subjects and thus requires different but collective properties in order to take on the great complexity of deciding the best material for money. For Jevons (1875), money should possess value and have utility at the basis of value as money is only received in order to be used (either in investment or consumption) in order to satisfy one's own ends. Money should also be portable and indestructible so that in can be transported to market with little to none transaction cost and able to be passed in trade countlessly or kept on reserve indefinitely (Jevons, 1875). Homogeneity and divisibility refer to the idea that money must be homogenous among its units and also (while referring to precious metals divisible so that the size is proportional to its value. A currency should finally be stability in its value and not subject to fluctuations and it should also be widely recognizable, distinguishable, and be established as a character of certain money of certain value (Jevons, 1875). While Jevons treatise of Money and the Mechanism of Exchange (1875) was rudimentary and generally applicable to commodity money, its principles can be applied in the debate of cryptocurrencies as alternative currency.' 


\section{The Case for Cryptocurrencies}

In his thesis of Economics of Bitcoin: Is Bitcoin an alternative to fit currencies and gold? (2012), Surda argues that Bitcoin poses as a serious alterative to fiat currency and commodity money like gold or silver and uses Mises' regression theorem to state this claim. Mises' regression theorem serves to explain how money achieves prices and that the origins of money are a market phenomenon. Surda (2012) first looks at the origin of money and finds that Bitcoin's origin is in direct relation with that of Mises' catallactic origin of money in that it was demanded by individuals in the market who arguably were biased against fractional-reserve, fiat money in the beginning of the great recession in 2008. Surda (2012) argues that bitcoin also meets the functionality of a medium of exchange due to its emergence of empirical price in the market as the rational expectations of the potential utility of bitcoin for potential buyers exceeded the price demanded by the producers and thus with competition on the supply side, trade emerged. Surda (2012) also argues that the emergence of liquidity also plays a role particularly with the Bitcoin market which allows for cryptocurrency exchange which opened in February of 2010. Surda, as a whole, argues that bitcoin meets the medium of exchange function of money due to bitcoins ability to have an emergence of price and an emergence of liquidity but argues that it fails to meet the store of value and unit of account functionality. Surda (2012) notes that bitcoin does have a comparative advantage over other mediums of exchange particularly fiat money and gold due to little transaction costs and a very inelastic money supply curve. Surda (2012) also states that due to the high volatility of bitcoin which is very much based on public perception that the store of value function and unit of account function are incredibly difficult to obtain at least in the early life of this new digital currency. Surda (2012) concludes his argument by stating that hypothetically market forces have the potential to make the evolution of Bitcoin 
into meeting the proper functionality of money but that due to so much uncertainty, a high level of specialization, and immature services, it just isn't there yet.

Fred Ehrsam, from the America's Quarterly (2015), argues that Bitcoin can empower Latin American entrepreneurs to tap into a truly global market by permitting them to accept payments from anywhere in the world without facing cross-border fees. Bitcoin bypasses the frictions traditionally associated with sending money from one country to another which is especially beneficial for entrepreneurship and remittance payments. This is particularly of significant importance in Venezuela as 95\% of exports are derived from oil production as Venezuela imports roughly two-thirds of its food needs. Historically and currently, cryptocurrencies are helping Venezuelans gain access to markets for which it cannot access with its current currency as its current currency lacks any sort of purchasing power and fails to function as a proper means of exchange in world markets.

Ehrsam (2015) also notes that in Latin America, 70\% of the population own mobile phones while only $40 \%$ have access to formal banking institutions or services thus with such a large connected population, Bitcoin is the perfect candidate to gain a foothold over alternative financial systems. Ehrsam (2015) states that in Latin America, all countries except Brazil have larger unbanked than banked populations. This is a massive socio-economic problem as the majority of individuals lack access to financial institutions and the current financial institutions are not adequately incentivized to serve the unbanked population (Ehrsam, 2015). There is an immediate, low-barrier solution and with cryptocurrencies anyone with internet access can receive wages and maintain savings in a secure, digital Bitcoin account at a very low cost to the user, and with no additional resources from local operators (Ehrsam, 2015). Bitcoins enable the secure and global storage and transmission of money without a bank account or credit card and 
thus can be seen as a mechanism to catalyze financial inclusion of the historically unbanked (Ehrsam, 2015).

Steve Patterson (2013), from the Foundation for Economic Education, also argues that cryptocurrencies are viable currencies in the short run but that in the long run the propensity to use any particular currency is rather unknown, not just for cryptocurrencies. Patterson (2013) uses Gold and Silver, the world's longest and perhaps most valuable currencies as examples and places long term viability as a function of Jevon's properties: cognizability, indestructibility, portability, utility/value, homogeneity, divisibility, and stability of value. According to Patterson (2013), Bitcoin meets the characteristics of portability, homogeneity, indestructibility as bitcoins are digital and can be sent electronically instantaneously and are also divisible as one bitcoin can be divided down to one hundred millionth of a bitcoin. The question that Patterson is struggling with is the notion of stability of value as the limited supply as bitcoin has a limited supply of 21 million units but the nominal price of a bitcoin is constantly fluctuating perhaps due to the market trying to adjust to speculators entering and leaving the market. Patterson (2013) cites this as non-important as it's clear the bitcoin has value and has so over several years despite the volatility and thus serves as a proper monetary currency meeting the values and qualities of those demanding it.

Jeffrey Tucker (2014), also from the Foundation for Economic Education, continues the discussion and argues that bitcoin has all the best features of money from history but adds a weightless and spaceless payment network that enables the entire world to trade. For Tucker (2014), cryptocurrencies, in general, are changing the game as they are attracting those in developing countries like Venezuela but also those in developed countries who have strong and reliable currencies. Tucker cites Carl Menger to cite that currency emergence is a market 
phenomenon and that the value and price of money are retrieved based on the amount of goods and services the particular currency can obtain. Money ultimately emerges as monetary entrepreneurs seek out an ideal form of commodity for indirect exchange thus making money the most marketable commodity. Tucker (2014) then looks at Mises' regression theorem in defense of value in bitcoin and notes that although Mises states that the initial value of money before it's a commodity is its direct utility, bitcoin is different because although bitcoin is nothing outside of exchanges, it's a currency and a payment system of significant value. For Tucker (2014), cryptocurrencies use value comes from its relationship with its payment system (the blockchain) as indicated in its first evaluation of 1309.03 bitcoin for $\$ 1$ U.S. dollar on the day of its release in January 2009. For this very reason, Bitcoin can be used and function as a means of exchange, unit of account, and store of value. 


\section{The Case Against Cryptocurrencies}

While several economists and scholars believe that cryptocurrencies are viable alternative currencies, many economists and academics don't think cryptocurrencies have the capacity to act as money. Jeffrey Dorfman (2017), cites that although Bitcoin has surged incredibly in the past few years making a good case for currency substitution but that bitcoin acts more like an asset than a currency. Dorfman (2017) notes that Bitcoin lacks two key characteristics to be able to be defined as a currency. The first is that bitcoin lacks a proper store of value. The importance of the store of value function of money cannot be understated due to a stable currency's ability to attract investment because those who invest are expecting a stream of future earnings to earn back their investment plus some profit. Instability in currency means that investors cannot accurately predict the value of those future earnings and thus make investments less valuable making less investment occur. In 2017, the U.S. dollar's exchange rate increased over the month by about 3\% while bitcoin's exchange rate rose by 49\% (Dorfman, 2017). In 2017, the U.S. dollar's exchange rate changed in a day by less than $1 \%$ while bitcoin's exchange rate changed by $3 \%$ (Dorfman, 2017). People don't want investments or debts denominated in a currency whose value can change by $50 \%$ in a month.

Jeffrey Dorfman (2017) also notes that the facilitation of transactions done by the blockchain is another factor inhibiting the store of value component of bitcoin. Dorfman (2017) notes that the general processing of bitcoin transactions is extremely slow and that due to a limit on the number of transactions that can be completed in a day, it can take several days to complete a transaction. Dorfman (2017) cites that its very security threatens its value in everyday use and that given recent investments by speculators, it's becoming more like a stock to earn a profit off of with a hugely growing bubble. Dorfman (2017) does note the expansion of 
cryptocurrencies but states that any sort of currency adoption or expectation is rather inconceivable.

Beliunas (2017) joins the discussion and also states that cryptocurrencies, particularly bitcoin, cannot be successful currencies. Beliunas (2017) cites the three characteristics for a successful currency; medium of exchange, store of value, and a unit of account and that Bitcoin only really settles one and a half of these functions. In terms of medium of exchange, Bitcoin is being accepted globally as money as large retailers, websites, and stores are gaining the infrastructure and are accepting Bitcoin as payment. When looking at the unit of account functionality, Beliunas (2017) notes that the volatility of bitcoin destroys any sort of real economic value that can be placed on assets, liability, goods, or services. Further, lenders don't use bitcoin as a unit of account for things like credit, loans or mortgages thus eliminating any sort of foundation for cryptocurrencies as a unit of account. The store of value function is where bitcoins and other cryptocurrencies get tricky as bitcoin does meet this function but more in terms of an asset like digital gold than as money. Beliunas (2017) looks at how valuable the asset is becoming in high inflationary economics like Zimbabwe and Venezuela where demand for the currency has skyrocketed and where consumers and businesses are demanding bitcoin for day to day purchases. As a whole, Bitcoin, according to Beliunas (2017), does not met the functions of a proper money and thus states that the future is quite unknown but that in terms of challenging developed currencies like the US. Dollar or Euro, is a stretch. 


\section{The Viability of Cryptocurrencies}

The debate regarding the viability of cryptocurrencies is one that is emerged and proliferated over the years since the first appearance and development of cryptocurrencies in the late 2000s and early 2010s. The scholarly debate of cryptocurrency viability materializes amongst economists and academics like Ehrsam, Tucker, Surda, Patterson, Dorfman, and Beliunas particularly in terms of the cryptocurrency's ability to meet the necessary characteristics and functions of money.

The debate regarding the viability of cryptocurrencies as alternative currencies is quite recent but much empirical work, time, and information is needed to understand where cryptocurrencies are headed in the short and long run. Some economists like Tucker and Patterson state that cryptocurrencies easily satisfy the three functions while economist Surda states that they have the general potential to meet this definition in the long run but that in the short run, as of current data, they fail to do so. Other scholars like Beliunas and Dorfman argues that although cryptocurrencies are becoming used more so as a medium of exchange, they are failing to meet the definitions of store of value and unit of account.

When it comes to Venezuela and the question of cryptocurrency viability, while the longterm viability remains a heated debate and topic of discussion, the viability issue is without a doubt undisputed. Cryptocurrencies are introducing and providing a means for Venezuelans to access goods in markets that Venezuelan bolivars cannot provide access to. Cryptocurrencies like bitcoin, litecoin, ripples and others are providing real solutions to the economic crisis that is plaguing the country of Venezuela. Cryptocurrencies might not be long term solutions but they are, at least in the short run, acting as currencies with a medium of exchange, store of value, and unit of account functionalities. 


\section{Discussion and Conclusion:}

In summary, the purpose if this thesis is to examine the origins, nature, and viability of cryptocurrencies in the hyperinflated country of Venezuela. The origins of cryptocurrencies in Venezuela relate directly to the macroeconomic and microeconomic policies set forth by the Chavez and Maduro regimes. The first economic policy taken into consideration is Chavez' restructuring of the Venezuelan economy which made the country susceptible to the Dutch Disease and allowed for government revenues to act as a function of solely international oil prices. The second economic policy taken into consideration is the redistributive land and wealth policies which have driven away foreign direct investments like Pepsi and ExxonMobil and destroyed the incentive system which allow individuals to trade and make society better off. The third economic policy considered is the price controls implemented by Chavez and furthered by Maduro which have distorted the pricing system and resulted in short-run shortages which have hurt consumers and producers. The fourth economic policy taken into consideration is the irresponsible government spending and monetary policy which lifted inflation to a projected level of $2300 \%$ and ultimately hurt consumers' purchasing power. The final economic policy considered is the fixed exchange rate system set in place by Chavez which allows for very limited exchanges to occur and extreme shortages to follow.

These economic policies contributed greatly to the current economic crisis and all seriously hurt the Venezuelan fiat money, the Venezuelan bolivar, and thus allowed for alternative currencies, like cryptocurrencies to emerge. Cryptocurrencies are decentralized, digital assets that are designed to work as a medium of exchange which uses cryptography to secure its transactions, control the creation of marginal units, and verify the transfer of these assets. These cryptocurrencies are great in that they are have relatively low transaction cost, 
cannot be traced by a third party, and allow Venezuelans to have access to larger, more open international markets for goods and services. Bitcoins in particular are providing Venezuelans with access to markets like Amazon, Walmart and other companies that use Bitcoin as a medium of exchange. John Villar notes that Bitcoins allow his family to easily import goods which he is unable to do with the Venezuelan bolivar and others are seeing this same trend as roughly a hundred thousand Venezuelans are using bitcoins as currency. Cryptocurrencies however require lots of energy, are heavily used in tax evasion schemes, and are used in drug and human trafficking cases regularly which could deter use and make the currency less effective.

This thesis concludes by discussing the feasibility of cryptocurrencies as alternative currencies in the hyperinflated country of Venezuela. This scholarly debate materializes amongst economists and academics in the early 2010s. Economists Ehrsam, Tucker, Patterson, and Surda all argue that cryptocurrencies function as money in that they meet the three functions of money (medium of exchange, store of value, and a unit of account). Tucker, Patterson, Ehrsam, and Surda all note that cryptocurrencies meet the three functionalities of money as well as Jevons' characteristics of money very well. Ehrsam also notes that Bitcoins are currencies which bypass traditional barriers associated with fiat currencies and can help the traditionally unbanked in Latin America. On the other hand, Dorfman and Beliunas note that cryptocurrencies do act as a proper medium of exchange but due to major volatility and instability compared to other currencies that these are merely assets and not currencies. Cryptocurrencies are introducing and providing a means for Venezuelans to access goods in markets that Venezuelan bolivars cannot provide access to. Cryptocurrencies like bitcoin, Litecoin, ripples and others are providing real solutions to the economic crisis that is plaguing the country of Venezuela. 


\section{Bibliography:}

Acheson, N. (2018, January 26). What is bitcoin? Retrieved February 17, 2018, from https://www.coindesk.com/information/what-is-bitcoin/

Alchian, A. (2007, September). Property Rights. Retrieved February 11, 2018, from http://www.econlib.org/library/Enc/PropertyRights.html

Althauser, J. (2017, December 16). Adoption of Bitcoin Picking Up Speed in Venezuela, Called "Lifesaving" Currency. Retrieved February 16, 2018, from https://cointelegraph.com/news/adoption-of-bitcoin-picking-up-speed-in-venezuela-calledlifesaving-currency

Althauser, Joshua. "Venezuelan Bitcoin Miners Turning to Ethereum After Government Crackdown.” Cointelegraph, 28 Aug. 2017, cointelegraph.com/news/venezuelan-bitcoin-minersturning-to-ethereum-after-government-crackdown.

Amadeo, K. (n.d.). Could You Survive Hyperinflation? Retrieved February 16, 2018, from https://www.thebalance.com/what-is-hyperinflation-definition-causes-and-examples3306097

Armario, C., \& Sanchez, F. (2017, December 14). Venezuelans facing currency crisis turn to bitcoin to survive. Retrieved February 16, 2018, from https://www.csmonitor.com/World/Americas/2017/1214/Venezuelans-facing-currency-crisisturn-to-bitcoin-to-survive

Armario, C., \& Sanchez, F. (2017, December 13). Venezuelans seeing bitcoin boom as survival, not speculation. Retrieved February 16, 2018, from https://www.seattletimes.com/business/venezuelans-seeing-bitcoin-boom-as-survival-notspeculation/

Aru, L. (2017, February 13). Nigeria is Following Venezuela's Bitcoin Trend | Iyke Aru. Retrieved February 17, 2018, from https://fee.org/articles/nigeria-is-following-venezuelasbitcoin-trend/

Bajpai, P. (2015, February 24). The Impact Of Venezuela's Bolivar Exchange Rates. Retrieved February 11, 2018, from https://www.investopedia.com/articles/forex/022415/impactvenezuelas-bolivar-exchange-rates.asp

Bauerle, N. (2017, March 17). What is Blockchain Technology? Retrieved February 17, 2018, from https://www.coindesk.com/information/what-is-blockchain-technology/

Beliunas, L. (2017, November 16). Bitcoin Not Currency, Never Will Be: Expert Blog. Retrieved February 18, 2018, from https://cointelegraph.com/news/bitcoin-not-currency-neverwill-be-expert-blog

Benzaquen, Mercy. "How Food in Venezuela Went From Subsidized to Scarce." The New York Times, The New York Times, 16 July 2017, www.nytimes.com/interactive/2017/07/16/world/americas/venezuela-shortages.html. 
C.W. (2014, November 05). What Dutch disease is, and why it's bad. Retrieved February 11, 2018, from https://www.economist.com/blogs/economist-explains/2014/11/economistexplains-2

Choudhury, Saheli Roy. "Bitcoin Is Exploding in Venezuela — but Not for the Reason You Think." CNBC, CNBC, 24 Aug. 2017, www.cnbc.com/2017/08/24/bitcoin-mining-ispopular-in-venezuela-because-of-hyperinflation.html.

Chun, R. (2017, August 08). Big in Venezuela: Bitcoin Mining. Retrieved February 16, 2018, from https://www.theatlantic.com/magazine/archive/2017/09/big-in-venezuela/534177/

Cove, R. (2017, November 20). How did Bitcoin come to be? Retrieved February 16, 2018, from https://marketrealist.com/2017/11/how-did-bitcoin-come-to-be

Desjardins, J. (2017, September 05). From Richer to Poorer: Venezuela's Economic Tragedy Visualized. Retrieved February 10, 2018, from http://money.visualcapitalist.com/richerpoorer-venezuela-economic-tragedy/

Disilvestro, E., \& Howden, D. (2015, December 28). Venezuela's Bizarre System of Exchange Rates. Retrieved February 14, 2018, from https://mises.org/library/venezuelas-bizarresystem-exchange-rates

Dorfman, J. (2017, May 17). Bitcoin Is An Asset, Not A Currency. Retrieved February 18, 2018, from https://www.forbes.com/sites/jeffreydorfman/2017/05/17/bitcoin-is-an-asset-nota-currency/\#3055e3ac2e 5b

Dornbusch, Rudiger, and Sebastian Edwards. The Macroeconomics of Populism in Latin America. National Bureau of Economic Research, 1989.

Durden, T. (2017, November 28). Valuing Bitcoin Using Metcalfe's Law. Retrieved February 16, 2018, from https://www.zerohedge.com/news/2017-11-28/bitcoins-valuation-usingmetcalfes-law

Durden, T. (2017, October). This Is What The Death Of A Nation Looks Like: Venezuela Prepares For 2,300\% Hyperinflation. Retrieved February 11, 2018, from

https://www.zerohedge.com/news/2017-10-10/what-death-nation-looks-venezuela-prepares-2300

Edwards, Sebastian. Crisis and Reform in Latin America: from Despair to Hope. Oxford University Press, 1999.

Ehrsam, F. (2015). Is Bitcoin Latin America's Next Big Thing? Retrieved February 17, 2018, from http://www.americasquarterly.org/content/bitcoin-latin-americas-next-big-thing

Ellsworth, B. (2014, January 24). Venezuela decrees new price controls to fight inflation. Retrieved February 11, 2018, from https://www.reuters.com/article/us-venezuelaeconomy/venezuela-decrees-new-price-controls-to-fight-inflation-idUSBREA0N1GL20140124

England, C. (2016, November 28). Venezuelas currency now worth so little shopkeepers weigh vast piles of notes instead of counting them. Retrieved February 16, 2018, from 
http://www.independent.co.uk/news/world/americas/venezuelas-currency-hyper-inflation-oilcrisis-devalued-shop-keepers-weigh-notes-a7443596.html

Fahey, M., \& Wells, N. (2016, November 20). Blame it on Caracas: Why these S\&P 500 giants are suffering from a Venezuelan hangover. Retrieved February 11, 2018, from https://www.cnbc.com/2016/11/16/venezuelas-crashing-economy-has-an-effect-on-us-corporateearnings.html? view=story\&\%24DEVICE\%24=native-android-mobile

Friedman, Uri. “How Populism Helped Wreck Venezuela.” The Atlantic, Atlantic Media Company, 4 June 2017, www.theatlantic.com/international/archive/2017/06/venezuelapopulism-fail/525321/.

Gillespie, P. (2017, November 22). Venezuela inflation soars to 4,000\% in death spiral. Retrieved February 16, 2018, from http://money.cnn.com/2017/11/22/news/economy/venezuelacurrency-crash/index.html

Gillespie, Patrick. "Venezuela Just Defaulted, Moving Deeper into Crisis." CNNMoney, Cable News Network, 14 Nov. 2017, money.cnn.com/2017/11/14/news/economy/venezueladebt-default-sp/index.html.

Gillespie, P. (2017, July 27). Venezuelans scramble for food, but it's often out of reach. Retrieved February 11, 2018, from http://money.cnn.com/2017/07/27/news/economy/venezuelafood-shortage/index.html

Golman, E. (2018, January 11). Cryptocurrency and Blockchain Explained Two Cryptocurrencies to Watch in 2018. Retrieved February 17, 2018, from https://www.huffingtonpost.com/entry/cryptocurrency-and-blockchain-explained-twocryptocurrencies_us_5a5515bde4b0cd114bdb36e3

Graham, L. (2017, April 24). Venezuela's asset seizures raises concerns for other sectors. Retrieved February 17, 2018, from https://www.cnbc.com/2017/04/24/venezuela-asset-seizuresraise-concerns-for-other-sectors-gm.html

Graham, L. (2017, February 20). Venezuela's crisis causes its people to cut meals and lose weight. Retrieved February 10, 2018, from https://www.cnbc.com/2017/02/20/venezuelascrisis-cause-its-people-to-cut-meals-and-lose-weight.html

Gross, J. (2014, October 30). 10 alternative currencies, from Bitcoin to BerkShares to sweat to laundry detergent. Retrieved February 18, 2018, from https://blog.ted.com/10alternative-currencies-from-bitcoin-to-berkshares-to-sweat-to-laundry-detergent/

Hackett, R. (2017, October 2). IMF Head: Cryptocurrency Could Be the Future. Really. Retrieved February 17, 2018, from http://fortune.com/2017/10/02/bitcoin-ethereumcryptocurrency-imf-christine-lagarde/

Hall, J. (2015, December 06). Fiat Currency: What It Is and Why It's Better Than a Gold Standard. Retrieved February 17, 2018, from 
https://www.fool.com/investing/general/2015/12/06/fiat-currency-what-it-is-and-why-its-betterthan-a.aspx

Hanson, S., \& Alvarez, C. (22009, February 09). Venezuela's Oil-Based Economy. Retrieved February 11, 2018, from https://www.cfr.org/backgrounder/venezuelas-oil-basedeconomy

Hausmann, R. (2017, July 31). Venezuela's Unprecedented Collapse . Retrieved February 10, 2018, from https://www.project-syndicate.org/commentary/venezuela-unprecedentedeconomic-collapse-by-ricardo-hausmann-2017-07?barrier=accessreg

Heath, H. (2016, June 15). Venezuela's Case of Dutch Disease: Cursed by Oil. Retrieved February 11, 2018, from http://www.panoramas.pitt.edu/economy-and-technology/venezuelascase-dutch-disease-cursed-oil

How Cryptocurrency is Disrupting the Global Economy. (2018, January 10). Retrieved February 10, 2018, from https://medium.com/the-mission/how-cryptocurrency-is-disrupting-theglobal-economy-89347581aa93

International Property Rights Index2017. (n.d.). Retrieved February 11, 2018, from https://www.internationalpropertyrightsindex.org/country/venezuela-bolivarian-republic-of

Iyenger, R. (2017, December 08). NiceHash: More than $\$ 70$ million stolen in bitcoin hack. Retrieved February 17, 2018, from http://money.cnn.com/2017/12/07/technology/nicehash-bitcoin-theft-hacking/index.html

Jevons, W. (1875). Money and the Mechanism of Exchange. New York, NY: Appleton and Co. .

Kleinman, J. (2018, January 17). Why Bitcoin's Price Is So Volatile. Retrieved February 17, 2018, from https://lifehacker.com/why-bitcoin-s-price-is-so-volatile-1822143846

Krauss, C., Casey, N., \& Vlasic, B. (2017, April 20). Amid Venezuela Protests, G.M. Plant Is Seized, and Company Exits. Retrieved February 11, 2018, from https://www.nytimes.com/2017/04/20/business/venezuela-general-motors-business-protests.html

Lieuwen, E., \& McCoy, J. L. (2018, January 19). Venezuela. Retrieved February 10, 2018, from https://www.britannica.com/place/Venezuela/The-economy

Martucci, B. (2017). What Is Cryptocurrency - How It Works, History \& Bitcoin Alternatives. Retrieved February 16, 2018, from https://www.moneycrashers.com/cryptocurrency-history-bitcoin-alternatives/

Navia, Patricio, and Andres Velasco. "The Politics of Second-Generation Reforms." Institute for International Economics, 2013.

Nino, J. (2016, August 17). Price Controls Are Disastrous for Venezuela, and Everywhere Else. Retrieved February 11, 2018, from https://mises.org/blog/price-controls-aredisastrous-venezuela-and-everywhere-else 
Patterson, S. (2013, December 11). Is Bitcoin a Viable Currency? Retrieved February 18, 2018, from https://fee.org/articles/is-bitcoin-a-viable-currency/

Pollock, Darryn. "Venezuelans Are Surviving In Crisis By Mining Bitcoin." Cointelegraph, 24 Aug. 2017, cointelegraph.com/news/venezuelans-are-surviving-in-crisis-bymining-bitcoin.

Rands, Kevin. "Why Venezuela's Currency Crisis Is A Case Study For Bitcoin.” Forbes, Forbes Magazine, 3 Feb. 2017, www.forbes.com/sites/realspin/2017/02/03/why-venezuelascurrency-crisis-is-a-case-study-for-bitcoin/\#61fcc90619b2.

Rodríguez, F. (2018, January 12). Why More Sanctions Won't Help Venezuela. Retrieved February 16, 2018, from http://foreignpolicy.com/2018/01/12/why-more-sanctions-wont-helpvenezuela/

Schwartz, E. (2016, July 12). The Dutch Disease in Saudi Arabia and Venezuela. Retrieved February 11, 2018, from https://econlife.com/2016/02/the-dutch-disease-that-saudiarabia-and-venezuela-share/

Schwartz, J. D. (2008, December 14). Alternative Currencies Grow in Popularity. Retrieved February 16, 2018, from http://content.time.com/time/business/article/0,8599,1865467,00.html

Shepherd S. (2018, January 30). Bitcoin Security Scrutinized After \$534 Million Stolen. Retrieved February 17, 2018, from https://securitytoday.com/articles/2018/01/30/bitcoinsecurity-scrutinized-after-534-million-stolen.aspx

Simoes, A. (2018). The Observatory of Economic Complexity: Venezuela. Retrieved February 10, 2018, from https://atlas.media.mit.edu/en/profile/country/ven/

Surda, P. (2012). Economics of Bitcoin: is Bitcoin an alternative to fiat currencies and gold? Nakamoto Institute. Retrieved January 21, 2018, from http://nakamotoinstitute.org/static/docs/economics-of-bitcoin.pdf

Taub, M. F. (2017, May 21). How Venezuela went from the richest economy in South America to the brink of financial ruin. Retrieved February 10, 2018, from http://www.independent.co.uk/news/long_reads/how-venezuela-went-from-the-richest-economyin-south-america-to-the-brink-of-financial-ruin-a7740616.html

TIMELINE-Hugo Chavez and Venezuela's oil industry. (2010, February 09). Retrieved February 11, 2018, from https:/www.reuters.com/article/venezuela-carabobo/timeline-hugochavez-and-venezuelas-oil-industry-idUSN0924439020100209

Tucker, J. A. (2014, August 27). What Gave Bitcoin Its Value?. Retrieved February 18, 2018, from https://fee.org/articles/what-gave-bitcoin-its-value/

Venezuela. (2017). Retrieved February 11, 2018, from https://www.heritage.org/index/country/venezuela 
Weisbrot, M., \& Sandoval, L. (July 2007). The Venezuelan Economy in the Chavez years. Center for Economic and Policy Research. Retrieved from

http://cepr.net/documents/publications/venezuela_2007_07.pdf

Young, J. (2017, October 17). Demand For Bitcoin in Venezuela is Increasing at an Exponential Rate. Retrieved February 16, 2018, from

https://www.newsbtc.com/2017/10/17/demand-bitcoin-venezuela-increasing-exponential-rate/

Zuñiga, Mariana. “Bitcoin 'Mining' Is Big Business in Venezuela, but the Government Wants to Shut It Down." The Washington Post, WP Company, 10 Mar.

2017, www.washingtonpost.com/news/worldviews/wp/2017/03/10/bitcoin-mining-is-big-

business-in-venezuela-but-the-government-wants-to-shut-it-down/?utm term=.a85ecb994095. 